\title{
200 años del Palacio de Minería: su historia a partir de fuentes documentales
}

200 Years of the Palacio de Minería (Mining Palace):

A History Based on Documentary Sources)

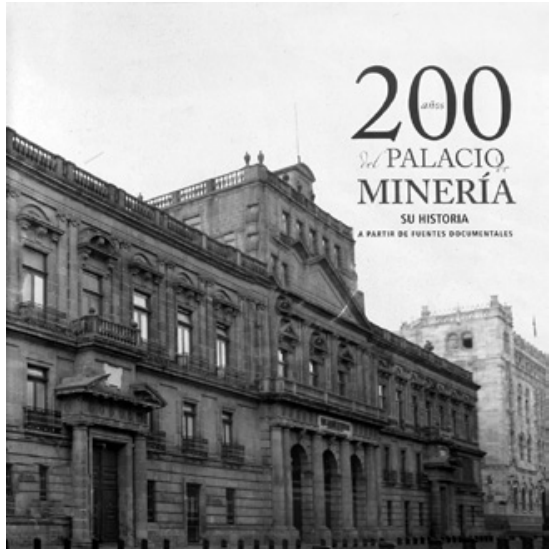

FIGURA 1. Portada del libro 200 años del Palacio de Minería: su historia a partir de fuentes documentales, Francisco Omar Escamilla González (coord.), México, FI-UNAM/Sociedad de Ex alumnos de la FI-UNAM, 2013.

\author{
Guadalupe de la Torre Villalpando \\ Escuela Nacional de Conservación, Restauración y Museografía (ENCRyM), \\ Instituto Nacional de Antropología e Historia (INAH), México \\ gdelatorre.deh@inah.gob.mx
}

\section{Resumen}

El libro 200 años del Palacio de Minería: su historia a partir de fuentes documentales es una obra conmemorativa producto de tres años de investigación de once profesionistas, congregados en un equipo interdisciplinario formado por historiadores, arquitectos, restauradores y sociólogos. El hilo conductor del texto es la historia de la construcción del antiguo Colegio de Minería de la ciudad de México, y de las intervenciones de que ha sido objeto a lo largo de estos dos siglos para mantener su integridad física y para adecuar sus espacios a nuevos usos que requería la enseñanza de la ingeniería, sin olvidar el contexto que hizo posible su edificación, las adaptaciones y su permanencia. Temas que los autores indagaron a partir de un conjunto de fuentes documentales importante y del estudio del propio edificio que conserva evidencias y huellas de diversas intervenciones.

\section{Palabras clave}

Palacio de Minería; Colegio de Minería; monumento histórico; Manuel Tolsá, Antonio Villard, México

\section{Abstract}

The book 200 años del Palacio de Minería: su historia a partir de fuentes documentales (200 Years of the Palacio de Minería [Mining Palace]: A History Based on Documentary Sources) is a commemorative work, product of a three-year research project fulfilled by an interdisciplinary team of eleven specialists consisting of historians, architects, restoration experts and sociologists. The central focus of the volume is the history of the construction of the ancient Mining School of Mexico City and of the interventions the building has undergone during the last two centuries: interventions carried out in order to maintain the physical integrity of the school of mining and to adapt its 
spaces to new uses required by the teaching of engineering - by taking into account the context that gave shape to the construction of the building, its modifications and its continuity. The authors explored those themes on the basis of a collection of important documentary sources, by studying the evidence the building itself that retains and the traces of its various interventions.

\section{Key words}

Palacio de Minería (Mining Palace); School of Mining Engineering; historical monument; Manuel Tolsá, Antonio Villard, Mexico

200 años del Palacio de Minería: su historia a partir de fuentes documentales (Escamilla González 2013a), publicado por la Facultad de Ingeniería de la Universidad Nacional Autónoma de México (FI-UNAM, México) y su Sociedad de Ex alumnos, salido de la imprenta en noviembre de 2013, es un libro colectivo conmemorativo a dos siglos de haberse concluido la edificación y de establecerse ahí el antiguo Colegio de Minería.

La obra es una magnífica edición de gran formato, de 708 páginas, con un índice onomástico y 294 imágenes; respecto de éstas, cabe destacar la excelente reproducción del material gráfico recopilado, labor significativa en sí misma, puesto que no simplemente ilustra los textos, sino es parte de la investigación. Esta indagación y rescate iconográficos incluyen material histórico del $\mathrm{Mu}$ seo Nacional de Historia del Instituto Nacional de Antropología e Historia (MNH-INAH, México), y del propio Colegio de Minería, consistente en fotografías, litografías o planos, así como en tomas fotográficas recientes y levantamientos en tercera dimensión, en los cuales se aprecian, por un lado, detalles tanto del sistema constructivo como de las etapas de edificación y las zonas afectadas por efecto de hundimientos diferenciales de la obra arquitectónica, y, por el otro, ilustraciones de la maquinaria y herramientas utilizadas en su construcción, entre otras. Por su parte, los pies de fotografía no sólo identifican la imagen en cuestión sino también ponen de relieve, mediante textos explicativos, su importancia y significación.

El libro es producto de tres años de investigación de once profesionales congregados en un equipo interdisciplinario de historiadores, arquitectos, restauradores y sociólogos provenientes de diferentes instituciones, entre las que se encuentran el propio INAH, la UNAM, la Universidad Iberoamericana (UIA, México) y el Archivo General de Notarías del Distrito Federal (AGNDF, México), quienes trabajaron integrados al seminario de investigación permanente "Constructores, mano de obra, técnicas y materiales de construcción en MéxiCO, siglos XVI-XX. El punto de vista social para los monumentos históri$\cos ^{\prime \prime}$, iniciativa de la Coordinación Nacional de Monumentos Históricos (CNMH-INAH, México).

No obstante que el Ilamado Palacio de Minería ha sido un edificio emblemático de la ciudad de México, el estudio de su construcción y de sus posteriores adaptaciones y restauraciones no se había llevado a cabo de manera tan rigurosa y exhaustiva. Como bien menciona Francisco Omar Escamilla González (2013b:35-39) en el prólogo de la obra que aquí se reseña, ya otros autores habían escrito sobre el tema, pero la fortuna de contar, de un tiempo a esta parte, con la documentación ordenada y catalogada del archivo histórico del colegio, ha hecho posible su consulta y, en consecuencia, la investigación a fondo y detallada del proceso constructivo del edificio de esta institución educativa. Cabe entonces reconocer los trabajos que antecedieron a este gran volumen y que han sido de consulta obligada para sus propios autores: Colegio de Minería, noticias sobre su origen y erección, de José María Castera (1841); Datos para la historia del Colegio de Minería, de Santiago Ramírez (1890), y las tres obras que llevan por título El Palacio de Minería: la de Manuel Francisco Álvarez (1910); la de Justino Fernández (1951), y la publicada por la Sociedad de Ex alumnos de la FI-UNAM (1977).

La interdisciplinariedad y el manejo de tan diversas fuentes son dos cualidades más de este libro. La búsqueda que sus autores emprendieron en una diversidad de acervos, entre los que, por supuesto, destacan el propio Archivo Histórico del Palacio de Minería (AHPM, México), el Archivo General de la Nación (AGN, México) y los archivos históricos del Distrito Federal "Carlos de Sigüenza y Góngora" (AHDF, México), el AGNDF y el de la Academia de San Carlos (ASC-UNAM, México), dan cuenta de la exhaustiva consulta de información documental, evidente, ya al analizar el aparato crítico que acompaña a los textos, ya en las tablas y apéndices que resumen cantidad de información y revelan horas y horas de trabajo laborioso. Además de estas fuentes, hay también un uso de material hemerográfico y de literatura de la época: obra de viajeros y diplomáticos, residentes temporales de la capital decimonónica que ilustra acerca del estado material del colegio en diferentes momentos.

Fuente imprescindible de primera mano, esencial en este caso, fue el propio edificio. En las visitas que realizaron los autores para reconocer los espacios y las intervenciones efectuadas a lo largo del tiempo se esclarecieron y entendieron, a partir de la documentación localizada, no sólo algunas de sus funciones sino que también, y en sentido contrario - pues el edificio conserva indicios o huellas de las reparaciones-, se confirmaron ciertas adecuaciones e intervenciones que permitieron obtener un seguimiento puntual de ellas y de las construcciones que han tenido lugar a lo largo de dos siglos, además de los protagonistas de tales obras y de los directivos o funcionarios, sin cuyo empeño no hubiera sido posible la edificación y -recalco- la conservación del colegio.

El libro, estructurado en once capítulos, hace un recuento minucioso de la historia de la vida material del 
edificio desde sus orígenes, pasando por las reparaciones apenas terminado, su reedificación, las diversas intervenciones para mantener su integridad estructural, las modificaciones para adaptar sus espacios a nuevos usos y la restauración de techumbres, pisos, pintura mural, ornamentación, etc.

No obstante, si bien se trata de una obra conformada para narrar cronológicamente dichas intervenciones al edificio, la secuencia de los capítulos no es del todo lógica con el propósito: hubiera sido deseable que los textos dedicados a las adecuaciones de espacios durante los siglos XIX y XX, a consecuencia de la demanda de nuevos usos, se agruparan después de los capítulos que describen obras de otra índole, las cuales respondieron a la necesidad de mantener el inmueble en pie y en buen estado.

Ahora bien, aunque la parte medular de la investigación es la historia de la construcción del inmueble (Alcántar y Soriano Valdez 2013a: 84-231; Guzmán y Rodríguez 2013a:232363), ésta no podría explicarse sin el contexto que la hizo posible ni sin considerar las condiciones que han logrado su permanencia, entornos que los autores abordan puntualmente en cada uno de los capítulos de la obra. Otro aspecto concomitante es el desarrollo de la institución en particular y de la ingeniería en general (Escamilla González 2013c:364403), que se explican por las modificaciones realizadas a los espacios del edificio tanto para adecuarlo al avance de la tecnología y a la modernización de la propia disciplina como para alojar otras dependencias ajenas a la Escuela Nacional de Ingenieros, hasta llegar a su conversión actual, como sede de la División de Educación Continua y a Distancia de la FI-UNAM (Escamilla González 2013b:36).

Como la mayoría de las instituciones borbónicas, el Real Colegio de Minería iniciaría sus labores en un edificio rentado que se adecuaría arquitectónicamente para albergarlo
(Sánchez Reyes 2013:78), pero, a diferencia de otras, como la Real Casa de Moneda -ahora Museo Nacional de las Culturas (MNC-INAH, México) — o la Real Fábrica de Tabaco, conocida como la Ciudadela, el primero mantuvo durante más de siglo y medio las funciones para las que fue concebido, y hasta el presente persiste en su vocación educativa.

Es precisamente en el primer capítulo del libro, "Sobre la venta del solar de Nilpantongo y las casas ahí construidas. La calle de Tacuba antes del establecimiento del Colegio de Minería", donde Gabriela Sánchez Reyes (2013:41-82) describe las circunstancias en que inicialmente se estableció el Colegio y los avatares para conseguir el terreno idóneo para levantarlo, a la vez que nos ambienta en el vecindario donde años más tarde se erigiría el Real Seminario de Minería.

Los siguientes cuatro capítulos, centrales a mi modo de ver, contienen vasta información de las obras de conservación del edificio a lo largo del siglo XIX, de los arquitectos e ingenieros que las idearon y llevaron a cabo, así como de los funcionarios y directivos interesados que las hicieron posibles (Alcántar y Soriano Valdez 2013a:84-231; Guzmán y Rodríguez 2013a:232-313). Esta parte del texto sigue un orden cronológico y abarca desde 1797, año del comienzo de la construcción del Colegio, hasta 1900; su investigación y escritura estuvieron a cargo de Iván Alcántar Terán, María Cristina Soriano Valdez, Virginia Guzmán Monroy y Leopoldo Rodríguez Morales.

Los dos primeros autores refieren, en el capítulo "La construcción del Real Colegio de Minería, 1797 1813" (Alcántar y Soriano 2013a: 84-171), las circunstancias en que se tomó la decisión de construir el edificio que daría cabida, más que dignamente, al Real Seminario de Minería; la elección del arquitecto que llevaría a cabo la obra, que fue, como es de todos conocido, el maestro Manuel Tolsá y Sarrión (1757-1816), y las vicisitudes de su edificación que, supeditada a la obtención de recursos y de materiales de construcción, en varias ocasiones causaron la suspensión temporal de la obra.

En un segundo capítulo describen cómo, mientras que una parte del edificio seguía en construcción (puesto que el Colegio se mudó a éste sin haber sido concluido), comenzaba la historia del salvamento de la obra en general (Alcántar y Soriano 2013b:172-231), a cargo de cuyas primeras reparaciones estuvieron los maestros en arquitectura Joaquín de Heredia y José Agustín Paz (Alcántar y Soriano 2013b:172-231). Pero, ¿cuáles fueron las razones de este deterioro estructural tan temprano? Los autores concluyen que se debieron a un problema multifactorial ocasionado, entre otras causas, por el terreno inadecuado, las características mismas del diseño arquitectónico y la falta de experiencia práctica del maestro Tolsá, problema éste que derivó en el hundimiento desigual del edificio, con la consecuente provocación de cuarteaduras, desnivel en las columnas y deformación de los arcos, entre otras afectaciones. Fue un momento difícil para el colegio, pues el Tribunal de Minería se encontraba en problemas económicos que le impedían enfrentar estos gastos, sumados a los de su construcción en proceso y a la oposición de un sector de la corporación que no estaba dispuesto a seguir sufragándolos (Alcántar y Soriano 2013b:172231). Un apartado interesante en esta parte del texto es el que los autores dedican a analizar la información localizada en el archivo histórico del colegio sobre las viviendas de que disponía la institución para arrendamiento (once accesorias y cinco entresuelos) y, por lo tanto, de financiamiento que, en un principio, incluso se utilizó para la propia construcción del edificio. El Colegio de Minería, en este sentido, no fue nada excepcional; como es sabido, esta costumbre, tan característica de la capital novohispana, de construir accesorias en las plantas bajas para 
conseguir recursos de las rentas, se observa lo mismo en casas señoriales, casas de vecindad y unifamiliares que en conventos e instituciones gubernamentales de la época (De la Torre, Lombardo y González 2001:109-146).

El capítulo dedicado a la intervención que hiciera el arquitecto Antonio Villard Olea entre los años 1827 y 1860 , cuya autoría se debe a Virginia Guzmán y Leopoldo Rodríguez (2013a:232-313), es crucial para entender la sobrevivencia del edificio: este personaje encabezó sus obras durante 33 años, los que a la postre garantizaron su preservación. De acuerdo con testimonios de la época, el colegio se encontraba en estado ruinoso cuando lo tomó en sus manos, lo que implicó realizar obras mayores y prolongadas para lograr la estabilidad de la construcción. Sólo por mencionar algunas de las obras correctivas más relevantes, cambió bóvedas de los pasillos por viguería (techumbre plana); sustituyó la bóveda de la escalera principal por una estructura de madera; desmontó columnas y arcos para corregir las afectaciones, y subió el nivel del piso del patio central (Guzmán y Rodríguez 2013a:232-313). Debe también reconocérsele al arquitecto Villard Olea la autoría de los planos más antiguos que se conservan del edificio, dado que los originales, trazados por Tolsá, no se han localizado (Guzmán y Rodríguez 2013a:232-313).

Los mismos dos autores describen cómo en la siguiente etapa, que va de 1860 a 1900, el edificio fue objeto de una serie de modificaciones que respondieron principalmente a la necesidad de adecuar sus espacios a nuevos usos (Guzmán y Rodríguez 2013b:314-363). En estos años los ingenieros Eleuterio Méndez, Francisco Serrano y Antonio M. Anza, profesores de la institución, participaron con el arquitecto Villard en las adecuaciones y adendas; para entonces, el colegio se había convertido en la Escuela Nacional de Ingenieros (1857), en la que, desde 1867, se había abierto la carrera de ingeniero civil (Guzmán y Rodríguez 2013b:314-363). Este último hecho, aunado al desarrollo de nuevas tecnologías, demandó áreas para la instalación de maquinaria y material de ensaye, lo que llevó a reformar el espacio originalmente ocupado por el comedor y la cocina del antiguo Colegio de Minería, donde se situó el Laboratorio de Química (1879) y, más tarde, el de Resistencia de Materiales (1892), en los que los ingenieros pondrían a prueba materiales y sistemas constructivos nuevos, como el concreto armado y las estructuras de hierro. A lo largo de este periodo, la Escuela Nacional de Ingenieros se vio confinada a una parte del edificio, mientras que, a finales del siglo $\mathrm{XIX}$, en el ala oriente, en lo que fuera la casa del director del colegio y parte de las accesorias en arrendamiento, se hicieron obras que ocuparía el Ministerio de Fomento (Guzmán y Rodríguez 2013b:314-363).

De sumo interés y utilidad es el trabajo de estos cuatro investigadores que resumen y presentan a manera de tablas los datos pormenorizados de los gastos de materiales, herramientas y pagos del personal que participó en las obras de reparación, restauración y adecuación en diferentes periodos y temporadas de trabajo, los cuales dan cuenta de los costos, procesos de trabajo, técnicas constructivas, diversificación de la mano de obra, artífices y trabajadores - en ocasiones, con nombre y apellido-, todos estos, autores materiales de la edificación.

Los siguientes cuatro capítulos del libro, en contraste con los anteriores, que nos hablan de la edificación en general, se enfocan en el estudio de ciertas intervenciones en particular. Me referiré ahora, específicamente, a dos de esos apartados: el primero, escrito por Mónica Silva Contreras (2013:494-539), dedicado a la bóveda que cubre la escalinata principal del colegio que fue una de las estructuras constantemente afectadas desde su origen, primero por hundimientos en el terreno, $y$, posteriormente por los constantes temblo- res que sufre la ciudad de México; para la primera mitad del siglo XIX, como se mencionó anteriormente, esta cubierta ya tenía problemas (Silva Contreras 2013:494-539). Una de las intervenciones del arquitecto Villard, realizada en la década de 1830, fue la sustitución de la bóveda proyectada por Tolsá por una de madera; a partir del análisis de imágenes (pinturas y litografías) y descripciones de la época, la autora (Contreras 2013:494-539) detalla su composición, considerando que el arquitecto la diseñó con una conciencia clara de conservar el carácter del edificio, y de integrarla al espacio a pesar de su modificación, en busca, ante todo, de dotarla de ligereza tanto estructural como visual. En 1874, a raíz de un temblor, la bóveda se vio de nuevo gravemente afectada; fue entonces cuando se impuso el empleo de innovadoras tecnologías para poder afrontar las enormes dificultades que implicaba encargar la estructura y traerla de Europa; por ello la escalera fue techada con una estructura de metal. La autora no se queda en este aspecto, sino que nos introduce en la polémica de aquel momento sobre el empleo de nuevas tecnologías en edificios fabricados con sistemas constructivos tradicionales (Silva Contreras 2013:494-539). Finalmente, en 1921 se decidió que la bóveda fuese otra vez objeto de la aplicación de técnicas constructivas innovadoras y que para una mejor conservación, se revistiera la estructura metálica con una cáscara de concreto armado.

Otro de los capítulos al que me quiero referir es el suscrito por Francisco Omar Escamilla González (2013c:364-403), quien muestra, como ejemplo relevante y significativo, la adecuación de un espacio antes destinado a comedor y cocina del antiguo Colegio de Minería, convertido en el primer laboratorio de ingeniería civil y, finalmente, destinado a alojar la Biblioteca Ing. Antonio M. Anza. Este trabajo es representativo por razón de que contiene evidencia de la historia de vida del inmueble; es decir, de la forma en que se transfor- 
mó para asilar otras funciones y de cómo se adaptó a estos cambios, en este caso concreto, en consecuencia con el desarrollo de la disciplina que le dio origen. Para finales del siglo XIX la Escuela Nacional de Ingenieros requería, acorde con los cambios en los planes de estudio y otras necesidades de enseñanza e investigación, nuevos espacios: el Laboratorio de Resistencia de Materiales daba servicio no sólo a los profesores y alumnos de la escuela sino también a empresas cementeras, metalúrgicas y petroleras, y a la misma Secretaría de Comunicaciones, que solicitaba pruebas de materiales, lo cual habla de la importancia del establecimiento y de la innovación de esta área de investigación aplicada (Escamilla González 2013c:364-403). Cuando, en 1973, se redescubrió este espacio, se destinó a hospedar los libros y publicaciones periódicas del Colegio de Minería y de la Escuela Nacional de Ingenieros que no se trasladaron en la mudanza de la Facultad de Ingeniería a la Ciudad Universitaria; efectivamente, como hace notar el autor (Escamilla González 2013c:364-403), cuando uno se encuentra en el suntuoso recinto de esta biblioteca es difícil imaginar que en los estantes y vitrinas se acumularan muestras de materiales de construcción, y que en el espacio central estuvieran instaladas máquinas de ensaye para probar la flexión de materiales, o bien para someterlos a compresión, pero las fotografías no dejan lugar a dudas.

El capítulo dedicado a la antigua capilla del Colegio de Minería merece especial atención (Avecilla y Alvarado 2013:540-595): se aboca a reconstruir la historia material de este espacio, en particular con base tanto en información documental como - lo más destacado- en la observación especializada de restauradores de bienes muebles. Jessica Avecilla Zapata e Iván Alvarado Camacho, parte del equipo que desarrolló el proyecto de restauración de la capilla, se dieron a la tarea de recopilar y sistematizar los datos do- cumentales encontrados, los cuales confrontaron $y$, en su caso, corroboraron, con las observaciones, los análisis de laboratorio y la información obtenida durante el proceso de restauración. Estos estudios, en conjunto con el análisis y el conocimiento de las restauraciones anteriores a las que se había sometido el recinto, dieron la pauta para tomar decisiones sobre su restauración. Este trabajo, por otra parte, viene a completar la narración del demorado proceso de conservación/restauración de que ha sido objeto el edificio desde su origen mismo.

Tras 200 años sorprende que el inmueble se mantenga en pie, puesto que sus problemas estructurales surgieron desde que estaba en construcción - los cuales no han dejado de ser materia de análisis de arquitectos e ingenieros-, y eso lo convierte en un testimonio vivo de muy diversos criterios y técnicas de restauración.

\section{Referencias}

Alcántar Terán, Iván Denisovich y María Cristina Soriano Valdez

2013a "La construcción del Real Colegio de Minería, 1797-1813", en Escamilla González (coord.) 2013a: 84-171. 2013b "El recinto de las ciencias entre puntales. Primera fase de reparaciones en el Colegio de Minería, 1813-1824", en Escamilla González (coord.) 2013a: 172-231.

Álvarez, Manuel Francisco

1910 El Palacio de Minería, México, Secretaría de Instrucción Pública y Bellas Artes.

Avecilla Zapata, Jessica e Iván Alvarado Camacho

2013 "La antigua capilla del Palacio de Minería. Un acercamiento a su historia a través de sus restauraciones: 1812-2012", en Escamilla González (coord.) 2013a: 540-595.

Boils Morales, Guillermo

2013 "Velaria en el patio central del Palacio de Minería", en Escamilla González (coord.) 2013a: 596-624.

Castera, José María

1841 "Colegio de Minería, noticias sobre su origen y erección", El Mosaico Mexicano VI: 145-158.

De la Torre Villalpando, Guadalupe et al. 2001 "La vivienda en una zona al suroeste de la Plaza Mayor de la Ciudad de México (1753-1811)", en R. Loreto López (coord.), Casas, viviendas y hogares en la historia de México, México, El Colegio de México, 109-146.

Escamilla González, Francisco (coord.) 2013a 200 años del Palacio de Minería, su historia a partir de sus fuentes documentales, México, FI-UNAM/Sociedad de Ex alumnos de la FI-UNAM.

Escamilla González, Francisco Omar 2013b "Prólogo", en Escamilla González (coord.) 2013a: 35-39.

2013c "El primer laboratorio mexicano de ingeniería civil, hoy Biblioteca Ing. Antonio M. Anza", en Escamilla González (coord.) 2013a: 364-403.

2013d "Orígenes de la carrera de ingeniería mecánica en México y el laboratorio de máquinas térmicas, hoy Salón Bicentenario: 1867-1924", en Escamilla González (coord.) 2013a: 404-449.

Fernández, Justino

1951 El Palacio de Minería, México, IIES-UNAM.

Guzmán Monroy, Virginia y Leopoldo Rodríguez Morales

2013a "Antonio Villard Olea y la reedificación del Colegio de Minería: 1827-1860", en Escamilla González (coord.): 2013a: 232-313

2013b "Intervenciones constructivas en la Escuela Nacional de Ingenieros: 1860-1900", en Escamilla González (coord.) 2013a: 314-363.

Morelos Rodríguez, Lucero 2013 "Las piedras del cielo de la Escuela Nacional de Ingenieros: 1893", en Escamilla González (coord.) 2013a: 450-493.

Ramírez, Santiago 1890 Datos para la historia del Colegio de Minería, México, Imprenta del Gobierno Federal.

Sánchez Reyes, Gabriela 2013 "Sobre la venta del solar de Nilpantongo y las casas ahí construidas. La calle de Tacuba antes del establecimiento del Colegio de Minería", en Escamilla González (coord.) 2013a: 41-82. 
Silva Contreras, Mónica

2013 "La escalera monumental del antiguo Colegio de Minería: de la composición académica a la moderna cubierta de hierro alemán, 1797-1929", en Escamilla González (coord.) 2013a: 494-539.

Sociedad de Ex alumnos de la FI-UNAM

1977 El Palacio de Minería, México, Sociedad de Ex alumnos de la FI-UNAM.

\section{Síntesis curricular del/os autor/es}

\section{Guadalupe de la Torre Villalpando}

Escuela Nacional de Conservación, Restauración y Museografía

(ENCRyM), Instituto Nacional de Antropología e Historia (INAH), México gdelatorre.deh@inah.gob.mx

Licenciada en historia del arte (Universidad Iberoamericana [UIA], México) y doctora en historia (Universidad Nacional Autónoma de México [UNAM], México). Curadora de pintura, escultura y estampa del Museo Nacional de Historia $(\mathrm{MNH})$, INAH, México, de 1978-1983. Investigadora de la Dirección de Estudios Históricos, (DEH), INAH, México, desde 1983 a la fecha, dentro de los seminarios de Historia urbana y espacio y estructura social en la ciudad de México. Titular de diversos proyectos de investigación relacionados con el desarrollo urbano de la ciudad de México en el siglo XVIII y autora de diversos artículos y libros sobre el mismo tema. Subdirectora de Investigaciones Históricas (DEH-INAH) en el periodo 1995-1999. En 2005 le fue otorgada la beca Ministerio de Asuntos Exteriores y de Cooperación, Agencia Española de Cooperación Internacional, España, para una estancia de investigación en archivos españoles y como profesora invitada en la Universidad Autónoma de Madrid (UAM), España. Actualmente es secretaria académica y de investigación, así como docente en la licenciatura en restauración y en las maestrías de conservación de acervos documentales, y de conservación y restauración de bienes culturales inmuebles en la ENCRyM-INAH, México. 